\title{
Analysis of Discontinuity in Visual Contours in Area 19 of the Cat
}

\author{
Hide-aki Saito, Keiji Tanaka, Yoshiro Fukada, ${ }^{a}$ and Hiroshi Oyamada ${ }^{1, b}$ \\ NHK Science and Technical Research Laboratories, Setagaya-ku, Tokyo, Japan 157, and 'Tohoku University, Faculty of \\ Electrical Engineering, Aoba, Sendai, Japan 980
}

Previous ablation studies have suggested that area 19 of the cat plays an important role in pattern discrimination. To clarify the functional roles unique to area 19, we studied the receptive-field properties of cells in area 19 and compared them with those of cells in area 17.

Recordings were made of anesthetized and immobilized animals. The majority ( $72 \%)$ of the cells in area 17 responded maximally to an elongated bar at a particular orientation, while they responded only weakly or not at all to a small spot (elongation-requiring cells). In contrast, more than half $(63 \%)$ of the cells in area 19 showed a good response to a nonoriented small stimulus moving in any direction (dot-responsive cells). Two-thirds of the dot-responsive cells in area 19 failed to respond when the moving slit was elongated to more than some length in any orientation. These dotresponsive cells of the "inhibited-by-length" type responded strongly to the end of a long bar, and many of them also responded strongly to a break point in the middle of a long bar. We suggest that these dot-responsive cells of the "inhibited-by-length" type detect discontinuities in contours.

Though they are in the minority, elongation-requiring cells constitute a considerable population $(37 \%)$ in area 19 , and dot-responsive and elongation-requiring cells form columnar patches in the same area. We conclude that, in contrast to area 17, whose main role is the decomposition of patterns into oriented contours, area 19 analyzes both orientation and discontinuities, with a strong bias towards the latter.

The cat's visual cortex is composed of a number of subareas [areas 17, 18, 19, the lateral suprasylvian visual areas (LS areas), etc.], each of which has its own retinotopic organization (Palmer et al., 1978; Tusa et al., 1978, 1979; Tusa and Palmer, 1980). Of these areas, the Clare-Bishop area, which is included in the LS areas, is thought to be concerned specifically with the analysis of visual motion, since it contains a high proportion of directionally selective cells (Spear and Baumann, 1975; Toyama and Kozasa, 1982; Toyama et al., 1986a, b).

Regarding form analysis, by contrast, knowledge is still very limited. Area 17 has been shown to be organized for the analysis

Received Feb. 4, 1987; revised Sept. 23, 1987; accepted Sept. 26, 1987.

We wish to thank anonymous reviewers for their excellent suggestions for improving the manuscript, especially for the suggestion of the name "dot-responsive cell" for our new proposal for the unique role of area 19 in pattern-information processing.

Correspondence should be addressed to Hide-aki Saito, Ph.D., NHK Science and Technical Research Laboratories, 1-10-11 Kinuta, Setagaya-ku, Tokyo, Japan and 157 .

a Present address: Department of Psychology, Teikyo University, Hachioji, Tokyo, Japan 192-03.

- Present address: Terumo Corporation, Fuji, Ohbuchi, Japan 417.

Copyright (C) 1988 Society for Neuroscience $0270-6474 / 88 / 041131-13 \$ 02.00 / 0$ of the orientation of contours (Hubel and Wiesel, 1962). However, we don't as yet understand the roles of the multiple extrastriate visual areas.

Lesion studies have suggested that some of the multiple visual subareas are more critically active in form analysis than are others. Doty (1971) showed that the ability of simple form discrimination (such as discriminating between a circle and a triangle) was not affected by a complete, but restricted, lesion of area 17 , but that it was severely impaired if the lesion included area 18 and most of area 19. Sprague and his colleagues showed that the combined lesion of area 19 and LS areas, but not a large lesion of areas 17 and 18, caused a severe deficit in such simple form discrimination (Sprague et al., 1977), as well as in the discrimination of the orientation of a dot array (Hughes and Sprague, 1986). These results suggest that area 19 is involved in form discrimination, and may carry out some analyses that are qualitatively different from those performed in areas 17 and 18.

Physiological studies have shown some quantitative differences among these areas: (1) Cells in area 19 are tuned to a slower movement of the visual pattern than are cells in areas 17 and 18 (Dreher et al., 1980; Duysens et al., 1982a, b). (2) Cells in area 19 are tuned to a spatial frequency intermediate between those of the cells in areas 17 and 18 (compare the results on area 19 by Tanaka et al., 1987, with those on areas 17 and 18 by Movshon et al., 1978). (3) The proportion of cnd-stopped cells is higher in area 19 than in area 17 (Hubel and Wiesel, 1965; Kimura et al., 1980; Duysens et al., 1982a; Tanaka et al., 1987). However, these are not qualitative differences.

We therefore reexamined the receptive-field properties of cells in area 19 to try to identify any uniqueness in the analysis performed in area 19 . We found that the majority of cells in area 19 do not require an elongation of stimulus along a special orientation for activation, and, instead, that a small stimulus activated them vigorously (they are referred to as dot-responsive cells). The response of most dot-responsive cells was eliminated when the stimulus was elongated to more than some length in any orientation. It was further found that almost all such cells responded strongly to the end of a long slit, and more than half of them responded to a break point in the middle of a long slit as well. These cells seem to be elaborated to detect discontinuities in contours and to neglect the continuous part of a long contour. The receptive-field mechanisms that underlie these properties and functional meanings will be discussed. Preliminary reports have been published elsewhere in abstract form (Saito et al., 1985, 1986).

\section{Materials and Methods}

Preparation and recording. Thirteen adult cats weighing $2.6-4.6 \mathrm{~kg}$ were used. The trachea was cannulated under anesthesia induced by halo- 

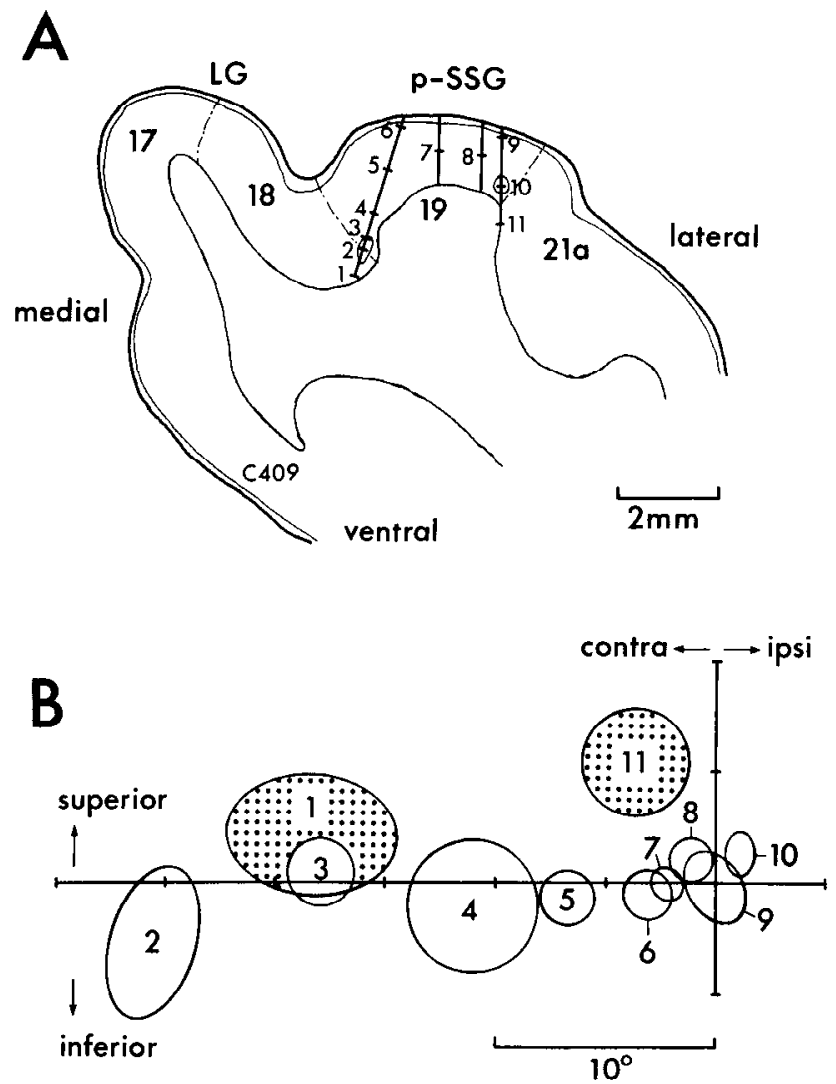

Figure 1. Identification of area 19. Reconstruction of penetrations made in a single frontal section of $P 4.0$ of a right hemisphere $(A)$ and receptive-field positions (RF positions) of recorded cells $(B)$. As the location of cells shifted from medial to lateral in p-SSG, RF positions changed regularly from a peripheral visual field (cell 2) towards the vertical meridian (cell 9). The RF position turned between cells $I$ and 2 at a peripheral visual field, and again between cells 10 and 11 near the vertical meridian, indicating that the area $18-19$ border lies between cells 1 and 2 , and the area 19-21a border between cells 10 and 11 . The approximate locations of these borders were determined with the aid of electric lesions made at recording sites of cells 2 and 10 . The area 18-19 border was confirmed by myelo- and cytoarchitectonic differences. $L G$, lateral gyrus; $p-S S G$, posterior suprasylvian gyrus.

thane (2-5\%) in a mixture of oxygen and air. The anesthesia was maintained with halothane $(1-2 \%)$ in a $70: 30$ mixture of nitrous oxide and oxygen throughout the operation. In addition, exposed tissue and pressure points were infiltrated with local anesthetic (xylocaine jelly). A brass block was attached to the top of the skull with bolts and acrylic resin, and the head was fixed to a Horsley-Clarke stereotaxic instrument by means of this block. The ear bars were used only temporarily, during the fixation of the brass block. Two small bolts for EEG recording were implanted near A-P zero. A craniotomy was made over P1-P7, L5-L1 2 of the occipital cortex, and a small durasectomy was made for microelectrodes. The femoral vein was cannulated.

After this, the animal was immobilized with gallamine triethiodide (an initial injection of $6 \mathrm{mg} / \mathrm{kg}$, i.v., followed by a continuous infusion of $5 \mathrm{mg} / \mathrm{kg} / \mathrm{hr}$ ) and artificially ventilated with a $70: 30$ mixture of $\mathrm{N}_{2} \mathrm{O}$ and $\mathrm{O}_{2}$. The rate of ventilation was fixed at $25 \mathrm{strokes} / \mathrm{min}$, and the stroke volume was adjusted so that the end-tidal $\mathrm{CO}_{2}$ concentration was maintained at $4.5-5.0 \%$. The animal was maintained in a state of light sleep (between stage II and stage III anesthesia; Ikeda and Wright, 1974) by adjusting the amount of additional anesthetic (pentobarbital sodium, $1-2 \mathrm{mg} / \mathrm{hr}$ ) in the continuous intravenous infusion fluid. The level of anesthesia was judged by monitoring the EEG. In the state of light sleep, the EEG exhibited a characteristic pattern, composed mostly of lowvoltage fast waves, with groups of high-voltage slow waves at intervals of about 3-5 sec. Control of the anesthetic state appears to be important in obtaining a stable response to photic stimuli from area 19 cells.
Though we have not compared the responses of the same cells at different levels of anesthesia, area 19 cells tended to respond very weakly and irregularly to repeated presentation of the same stimulus, or not even to be activated at all when the anesthesia was judged to be insufficient from the EEG pattern. This is very different from the case of area 17 cells, which responded clearly to photic stimuli during the state of arousal (cf. Livingstone and Hubel, 1981).

Extracellular recordings were made with glass-coated platinum-iridium microelectrodes (exposed tip length, $10-15 \mu \mathrm{m} ; 2-4 \mathrm{M} \Omega$ at $1 \mathrm{kHz}$ ) from the posterior suprasylvian gyrus (within a square region of P2-6, L6-10 of the Horsley-Clarke coordinate). Usually, the electrodes penetrated the cortex with their axes vertical to the cortical surface. Single units were isolated at roughly regular intervals $(100-200 \mu \mathrm{m})$ in order to study cells of different layers equally. Several tangential penetrations were also made in order to examine the spatial clustering of cell types on an axis parallel to the cortical surface. In such cases, the electrodes were introduced from the anterior side (entering the cortex at P1, L78 ) and were advanced in the parasagittal plane posteriorly. In many penetrations, small electrical lesions were made by passing a weak current $(10 \mu \mathrm{A}, 10 \mathrm{~min}$, electrode tip negative) at $1-3$ points to assess the position of the recorded cells.

Area 17 cells were also recorded in the medial bank of the lateral gyrus (P3-5) in different sessions of the experiments. This was done so that we could make a direct comparison of the responses of cells in the 2 areas.

After the end of the experiments, the animals were killed with an overdose of sodium pentobarbital, and the brains were perfused with warm saline and then with $10 \%$ formalin. Frontal sections, $50 \mu \mathrm{m}$ thick, were made and stained either for cell bodies (Nissl staining with cresyl violet) or for fibers (myelin staining by Benda-Spielmeyer methods). Electrode tracks were reconstructed with the aid of electrical lesions and track traces to ascertain the localization of the cells studied.

Identification of area 19. According to Tusa et al. (1979), the borders between area 19 and the surrounding areas of the posterior suprasylvian gyrus can be determined by systematic retinotopical mapping. That is, within area 19 , the contralateral visual hemifield is mapped in retinotopical order so that the lateral periphery is represented most medially and the vertical meridian most laterally. The receptive-field position turns at the periphery of the visual field on the borders of areas 18 and 19 , and at the vertical meridian on the borders of areas 19 and $21 \mathrm{a}$.

We have confirmed this retinotopic relationship for several hemispheres by making several penetrations at different mediolateral positions in the same frontal plane. An example is shown in Figure 1. As the location of the recorded cell moves from medial to lateral, the receptive-field position changes systematically from the periphery towards the vertical meridian. In the most medially situated penetration (which was inclined slightly), a reversal of the positional shift of the receptive field occurred between cells 2 and 1 . In addition, cell 1 exhibited a particular preference for a fast-moving visual stimulus. These facts indicate that the borders of areas 18 and 19 lay between these two cells. An electric lesion was made here. The reversal of positional shift was also observed between cells 10 and 11 in the most laterally placed penetration. This time, the reversal occurred near the vertical meridian. We judged that the electrode entered area 21 a here. We did not observe any sharp differences between the receptive-field properties of cells of areas 19 and 21 except that the size of the receptive field was somewhat larger in area $21 \mathrm{a}$ than in area 19. For the other hemispheres, for which only a few penetrations were made, we considered that the penetration was within area 19 if more laterally situated penetrations sampled cells with more medially situated receptive fields.

In the tangential penetrations, which were directed anteroposteriorly, the electrodes entered area $21 \mathrm{a}$ first, traversed area 19 , and finally reached area 18 at the posterolateral sulcus. The borders were determined by the positional relationships of the receptive fields of successively recorded cells. The difference in velocity preference assisted in the determination of the border between areas 18 and 19 .

Photic stimulation. The cat's eyes were fully dilated and the nictitating membranes retracted with phenylephrine hydrochroride. Contact lenses of appropriate power were attached to both eyes, to focus the photic stimulus on the retina and to prevent the cornea from drying. Artificial pupils ( $2 \mathrm{~mm}$ in diameter) were placed in front of the contact lenses to reduce refractive error.

During a preliminary survey of the receptive-field properties of cells in area 19, we confirmed previous studies (Duysens et al., 1982a, b) that have shown many cells to be selective for the orientation of a bar, 
and that a substantial proportion of them do not respond at all to a long bar. We noticed, however, that many of the cells gave a submaximal response to a small dot. This implies that the elongation of a contour along some particular orientation axis is not essential to activation. In other words, such cells, though they show orientation selectivity for a bar of some length, do not form part of the extractor of the feature "orientation," as they cannot distinguish a small spot from a bar in some particular orientations. This forced us to reexamine the classification of the cells in area 19 from a functional viewpoint. To do this, we conducted a length-response analysis with slits or bars in several different orientations ( 2 orthogonal orientations routinely, and some additional ones between). This permitted us to assess the length sensitivity and orientation selectivity of cells at the same time.

On a tangent screen placed $57 \mathrm{~cm}$ from the cat's eyes, a light slit or a dark bar of variable size was projected from the rear. The light source was a halogen lamp. The screen was illuminated from the front at about $3 \mathrm{~cd} / \mathrm{m}^{2}$ by distant fluorescent lamps. The luminance of the light spot and the slit was about $50 \mathrm{~cd} / \mathrm{m}^{2}(1.2 \mathrm{log}$ units brighter than the background). When a dark bar was projected, the luminance of the background was increased to about $70 \mathrm{~cd} / \mathrm{m}^{2}$, and the dark bar was about $1.3 \mathrm{log}$ units darker than the background. Since cells in area 19 are generally more sensitive to a moving stimulus than to a flashing stationary stimulus, an analysis was made by moving the stimulus back and forth across the receptive field. When the stimulus was a bar, it was moved in a direction orthogonal to its orientation. The stimulus was moved by using a mirror mounted on a galvanometer, and the speed of movement was set at the optimum for each cell.

When a cell was isolated, its receptive field was mapped on the screen, and its orientation selectivity was examined by using hand-moved slits of various lengths. If a preference for a particular orientation was found in this way, one orientation to be examined was set at this orientation. If such a preferred orientation could not be found by using slits of any length, a length-response analysis was performed for horizontally and vertically oriented slits. Using hand-held bars, we ascertained that there was no sharp dip in the response for intermediate orientations. For some cells, we did a length-response analysis for slits at 2 additional orientations, $45^{\circ}$ from the standard orientations.

The width of the stimulus was fixed near the cell's optimum value $\left(0.5^{\circ} \mathrm{step}\right)$ and its length was changed systematically from $0.5^{\circ}$ or $1^{\circ}$ to $64^{\circ}$ in doubled steps. The slit (or bar) was aligned so that its center always passed through the center of the receptive field.

We employed 3 kinds of discontinuity stimulus: a square spot $\left(0.5^{\circ} \times 0.5^{\circ}\right.$, or $1^{\circ} \times 1^{\circ}-$ a point discontinuity), the end of a long slit (termination) and a break in the middle of a long slit (midbreakinterruption-discontinuity). The midbreak was produced by masking the center of the projected slit with a long, narrow opaque sheet $\left(0.5^{\circ}-\right.$ $3.0^{\circ}$ in width). The sheet was attached to the screen from behind to make it almost invisible.

Peristimulus time histograms (PSTHs) were compiled for the response to 10-20 stimulus repetitions. The response magnitude was measured by subtracting the hackground discharge rate from the peak discharage rate elicited by the stimulus. We calculated the peak discharge rate by taking the mean value of counts for 3 bins (bin width was usually 250 msec), including a bin that contained the maximum discharge count. The mean rate of discharge measured for $1 \mathrm{sec}$ before the presentation of the stimulus was taken as the background discharge rate.

\section{Results}

\section{Classification of cells in area 19 according to length-response} properties

Two hundred and seventy cells were isolated in area 19 . Of these, 194 cells $(72 \%)$ responded to a light slit and/or a dark bar consistently; therefore their receptive-field properties could be explored systematically. Cells in which the response was too weak for the receptive-field properties to be examined ( 27 cells) were left unclassified. Forty-nine cells were not responsive to light slits or dark bars. No such cells responded to more complex stimuli, such as stripes, a star-shaped patch, photographs of a human face and hand, real faces and hands, etc. It was noted that the percentage of unresponsive cells in area $19(18 \%)$ was
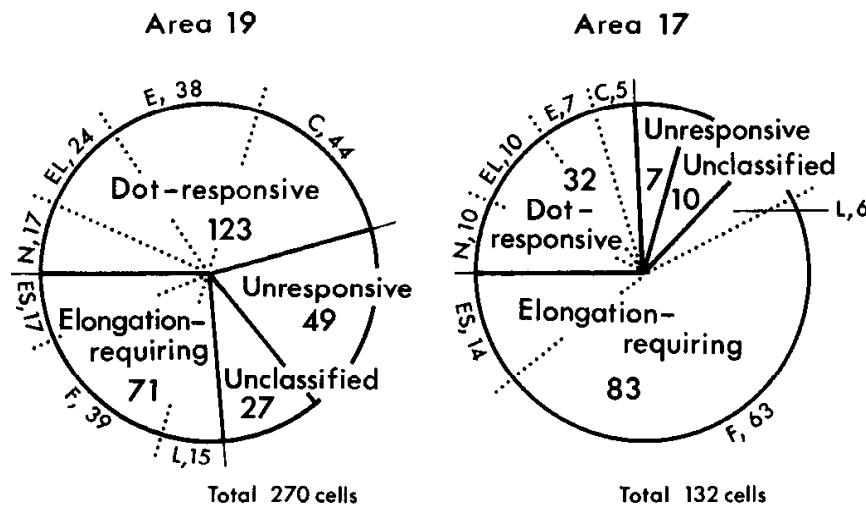

Figure 2. Proportion of dot-responsive and elongation-requiring cells in areas 19 and 17. Dot-responsive and elongation-requiring cells are further divided into subclasses, as indicated by abbreviations. Subclasses of dot-responsive cells: $C$, circular; $E$, elliptic; $E L$, elongated; $N$, nonselective. Subclasses of elongation-requiring cells: $E S$, end-stopped; $F$, end-free; $L$, long. The number of cells is indicated.

higher than in area 17 (5\% of 132 isolated cells) in the present series of experiments.

According to differences in the length-response properties, the visually responsive cells in area 19 were classified into one of 2 classes, namely, "dot-responsive" or "elongation-requiring." The classification was made as follows. First, we measured the length-response properties for 2 or 4 orientations, one of which was set at the preferred orientation, if one existed. We then classified the cell as dot-responsive if its response to a $0.5^{\circ} \times 1^{\circ}$ bar or to a $1^{\circ} \times 1^{\circ}$ square in any orientation was larger than $50 \%$ of the maximum response. Of the rest, a small number of cells (6) in which the response to bars of some particular length was larger than $50 \%$ of the maximum at any orientation was also classified as dot-responsive, since it was determined by noting the cells' responses to larger squares $\left(2^{\circ} \times 2^{\circ}, 4^{\circ} \times\right.$ $\left.4^{\circ}\right)$ and spots $\left(2^{\circ}-4^{\circ}\right.$ in diameter) that the feature required to activate such cells was not an elongation of the bar along some particular orientation axis, but simply the size of the dot. The remaining cells were classified as elongation-requiring, as their response to an elongated bar was more than twice as large as their response to smaller, nonelongated stimuli. All the elongation-requiring cells were orientation-selective. By contrast, not all the dot-responsive cells were orientation-insensitive. Dotresponsive cells of the subclasses "elliptic" and "elongated" (the characteristics of each type are described below) were sensitive to the orientation of an elongated bar stimulus.

A prominent difference between areas 19 and 17 has become evident because of the introduction of this new classification: Dot-responsive cells (63\% of the classified cells) are twice as common as elongation-requiring cells in area 19, whereas the vast majority (72\%) of the classified cells in area 17 are of the elongation-requiring type (Fig. 2). (Elliptic and elongated dotresponsive cells are sensitive to the orientation of a bar of some length. Therefore if the cells are classified according to their sensitivity to the orientation, the percentages of orientationsensitive cells in areas 19 and 17 are $69 \%$ and $87 \%$, respectively.) The retinal eccentricity of the receptive field of recorded cells in both areas are distributed from $0^{\circ}$ to $20^{\circ}$, with a big bias within $10^{\circ}$; and at any region of the eccentricity, the dot-responsive cells overwhelm the elongation-requiring cells in area 19 , while the reverse is true in area 17. Thus, a high incidence 
Figure 3. Length-response properties of a dot-responsive cell. For all orientations tested, this cell always gave the strongest response to the shortest slit $\left(0.5^{\circ}\right.$ in length) used in the present study. The PSTHs and length-response plots are given for 2 orientations: one along the major axis of the receptive field (PSTHs, left column; filled circles, top right graph) and the other orthogonal to this (PSTHs, right column; open circles, top right graph). An elongation of the slit in any orientation eliminated the cell's response. The length for which a $50 \%$ reduction was achieved differed for different orientations. This cell was thus classified as of the elliptic type of dot-responsive cell.
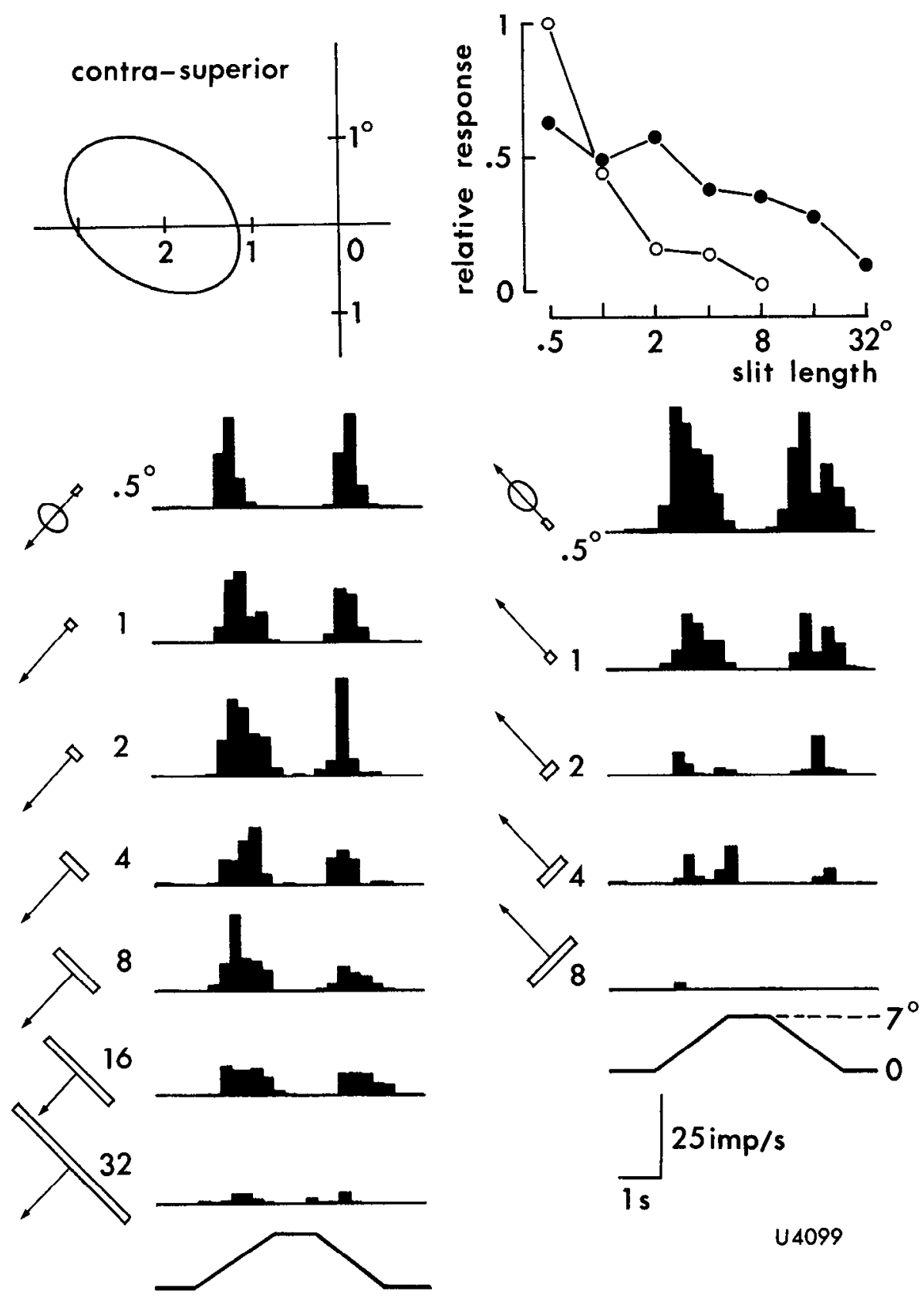

U4099 of dot-responsive cells is a genuine feature of area 19. Another important result of our classification is the discovery of columnar patches within area 19.

\section{Dot-responsive cells}

Dot-responsive cells have a common property: they give a good response to the appearance of a small stimulus that has no orientation, although their response to an elongated bar stimulus is not uniform. Some cells show selectivity to the bar orientation for some range of bar length, while others do not.

To clarify the difference between our classification and the "oriented/nonoriented" classification that has been widely adopted by earlier workers, we shall first describe the lengthresponse profiles of a dot-responsive cell sensitive to the orientation of a bar of some length. A typical example is given in
Figure 3. The responses of the cell to slits oriented along the long axis of the oval receptive field, and to others oriented orthogonally, are shown in the left- and right-hand columns of Figure 3. This cell exhibited selectivity for orientation when tested with a slit $2^{\circ}-16^{\circ}$ in length, and would therefore be classified as orientation-selective if the stress were put on sensitivity to orientation. However, we classify the cell as dot-responsive, since we put the stress on the responsiveness of the cell to a small and nonoriented stimulus. This cell always showed its strongest response for the shortest slit $\left(0.5^{\circ}\right)$, irrespective of its direction of motion. (In the present study, we used a moving slit preferentially. We defined its orientation, orthogonal to its direction of movement, as the "orientation" of the slit and its extent along this orientation as its "length," irrespective of its relative length and width.) Though there was substantial im- 
balance in the magnitude of response to the shortest slit, depending on its direction of motion (Fig. 3), the minimum : maximum ratio was greater than 0.5 .

In two-thirds $(67 \%)$ of the dot-responsive cells in area 19 , the elongation of the slit to more than some optimal length in any orientation resulted in a reduction of the response by more than $50 \%$. In some dot-responsive cells, a $50 \%$ reduction was reached at almost the same slit length in all orientations. Such cells were classified as "circular" ( $36 \%$ of the dot-responsive cells). An example is given in Figure 4 , in which the length-response analysis was made using slits at 4 orientations in $45^{\circ}$ steps. In other cells, the length at which the response was reduced to $50 \%$ was different (by more than $2: 1$ ) for the 2 orthogonal orientations. Such cells were called "elliptic" (31\%). The cell shown in Figure 3 belongs to this subclass. We noticed that in some circular and elliptic cells, the most effective stimulus was a slit whose width was larger than its length. These cells may correspond to the rectangle cell of Duysens et al. (1982b).

Of the rest, a reduction of more than $50 \%$ was seen only for a limited range of orientations in some cells ("elongated," 19\%), and the response was not reduced to less than $50 \%$ of the maximum response for any orientation in the others ("nonselective," $14 \%)$.

Because of the oricntation imbalance of the length for which a response-reduction occurred, the elliptic and elongated types of dot-responsive cells exhibited orientation selectivity for bars of some length.

\section{Elongation-requiring cells}

Elongation-requiring cells are unique in that they do not respond to nonoriented small stimuli. A typical elongation-requiring cell from area 19 is illustrated in Figure 5. The PSTHs in the leftand right-hand columns show the length-response characteristics of the cell to slits in the optimal orientation (4-10 o'clock) and to slits at the orthogonal orientation. The width of the slit was $1^{\circ}$. The cell gave only a weak response when the length was $1^{\circ}$. Elongating the slit in the optimal orientation increased the magnitude of the response. The maximum was reached at the length of $4^{\circ}$. The cell gave only a feeble response (less than $20 \%$ of the maximum) to a slit of any length in the orthogonal orientation. This cell exhibited selectivity to the direction of motion, in addition to orientation.

Figure 5 also shows the end-stopping property of the cell; that is, elongating the slit to more than $4^{\circ}$ resulted in a sharp reduction in the magnitude of the response. The cell may thus correspond to the lower-order hypercomplex cell of Hubel and Wiesel (1965). We call this type of cell "end-stoppcd."

Quantitatively, a cell was classified as end-stopped if elongating the slit to more than the optimal length reduced the magnitude of the response by more than $50 \%$. If there was no reduction, or if the reduction was less than $50 \%$, the cell was classified as end-free. About $24 \%$ of the elongation-requiring cells were end-stopped according to this criterion. End-inhibitory zones seemed to be present at both sides of the excitatory zone in most end-stopped cells, since the response was eliminated when the slit was asymmetrically elongated to more than the excitatory receptive field in either direction along the orientation axis. The optimal slit length for these cells ranged from $2^{\circ}$ to $8^{\circ}$. For the other cells, the response was eliminated only when the slit was elongated in one of the 2 directions (singlestopped cells). We gave a special name, "long," to end-free cells that responded best to slits $16^{\circ}$ or more in length.

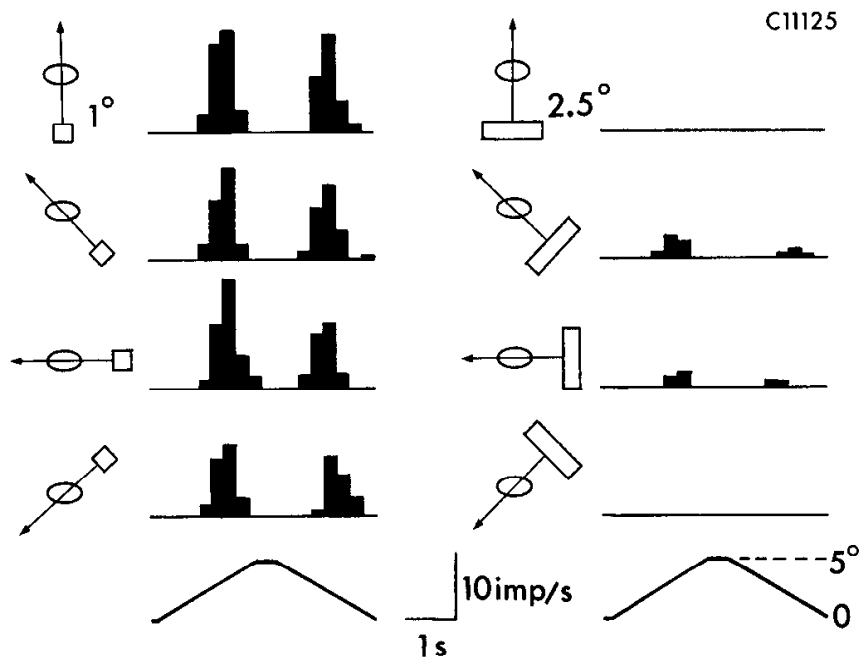

Figure 4. Example of a circular dot-responsive cell. The cell responded strongly to $1^{\circ} \times 1^{\circ}$ slit, but the response disappeared almost completely when the slit was elongated to $2.5^{\circ}$ in any orientation.

\section{Columnar organization of area 19}

The sequence of cell types sampled in several penetrations of area 19 is shown in Figure 6. In each penetration that passed through the cortex almost perpendicularly to the layers, the cells recorded over the entire depth (layers II-VI) were almost exclusively of the dot-responsive type (Fig. 6, $A, B, C$ ) or of the elongation-requiring type (Fig. $6 F$ ). In oblique and tangential penetrations, on the other hand, 2 types of cells were recorded alternately in a grouped fashion (Fig. $6, D, E, G-J$ ). This indicates that, in area 19, dot-responsive and elongation-requiring cells are segregated to form columnar patches, each of which runs through all the cortical layers. Columnar patches of dotresponsive cells may be bigger than those of elongation-requiring cells.

As for the subclasses, either of dot-responsive or elongationrequiring cells, neither patchy organization nor layer segregation was obvious, although there was a tendency for cells of each subclass to be recorded in a grouped fashion.

\section{Response of dot-responsive cells to discontinuities in contours}

As described above, an elongation of a slit to more than a given length eliminates the response of the majority of dot-responsive cells. Superficially, this property seems to be similar to that of orientation-selective cells of the end-stopped type, for which it is suggested that the function of end-stopping is to code the length of the contour. However, since such dot-responsive cells respond well to a short slit, and the magnitude of the response is more or less constant until the length of the slit reaches a particular value, they cannot code a particular length of contour. What, then, is the functional meaning of such strong suppression followed by elongation? We hypothesize that a possible function is to neglect the continuous part of a contour for the effective analysis of a discontinuity. Cells of circular and elliptic type are especially suited to perform such analysis because they neglect a long contour at any orientation. We, therefore, systematically examined the response of circular and elliptic cells (they will be referred to as dot-responsive cells of an inhibitied-by-length type, or I-L-type dot-responsive cells) to 2 kinds of discontinuity: an end and a break in the middle of a long slit (midbreak). 
Figure 5. Length-responsc propertics of an elongation-requiring cell. This cell gave a maximum response to a 4-10 $0^{\prime}$ clock-oriented slit $4^{\circ}$ in length. PSTHs, left and right columns, show length-response properties for slits in the preferred orientation and in the orientation orthogonal to this. Length-response plots calculated for these PSTHs are given at the top right (filled circles, preferred orientation; open circles, orthogonal orientation). The response to the slit in orthogonal orientation was less than one-quarter the maximum responsc of the cell, irrespective of the length. The response of the cell to the slit in the preferred orientation was reduced sharply to less than one-quarter of the maximum when the length of the slit was shortened to one-quarter, or elongated to 4 times, the optimal length. This cell was thus classified as an endstopped, elongation-requiring type. The receptive-field position and size are given at the top left. Short bars attached to the ellipse indicate the preferred orientation of the cell.
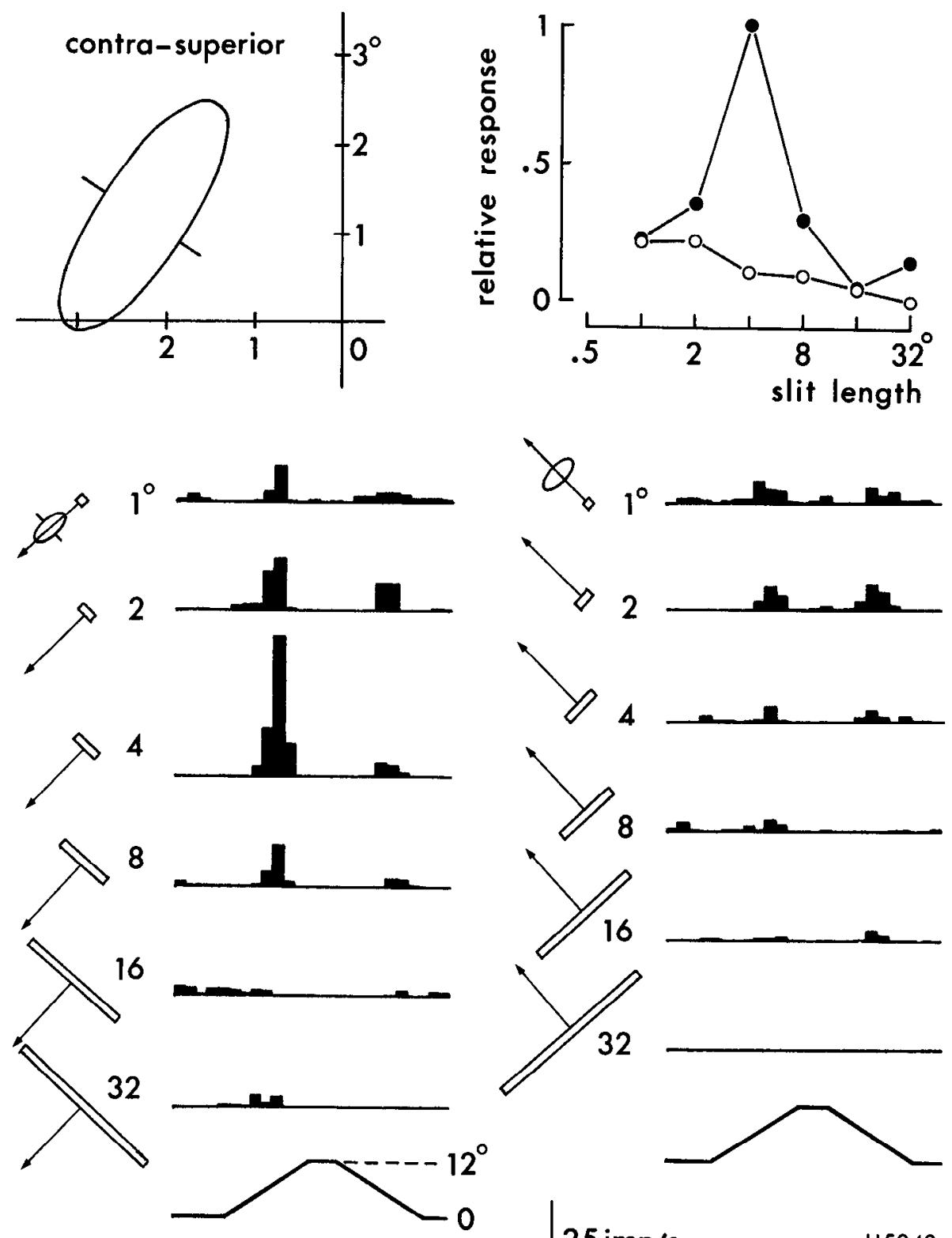

2

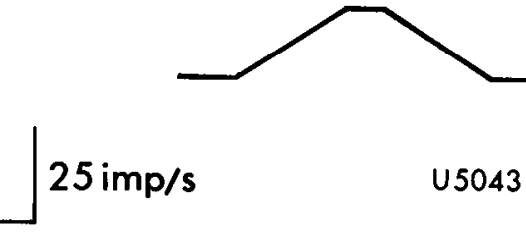

$1 \mathrm{~s}$
An example of experiments carried out on an elliptic cell is shown in Figure 7. As shown on the left side, the reduction of the response caused by a symmetrical elongation of the slit was almost complete. However, the cell gave an almost maximal response to the end of a long slit, as is shown on the right. The majority ( $87 \%$ ) of I-L-type dot-responsive cells ( 46 cells tested) were activated almost maximally by the end of a long slit. Neither the direction from which the end of a bar extruded nor the direction of movement of the stimulus was crucial for activating most of them. Thus, it was verified that I-L-type dot-responsive cells respond fairly strongly to the passage of a small object as well as to the end of a line over the excitatory receptive field, but that they ignore the passage of a continuous part of a long line.

The most exciting phenomenon observed in some I-L-type dot-responsive cells is illustrated in Figure 8. This cell was clas- sified as being circular in type. As is shown at the top right, the cell did not respond at all to a moving long slit extending in both directions across the excitatory region. When a narrow band across the center of the receptive field was masked from stimulation by attaching a narrow opaque sheet (mask) to the screen from behind, the cell responded strongly to the movement of the same long slit, as is shown in the lower 2 records on the right. This was surprising, becausc the masked region is the most sensitive excitatory region of the receptive field. PSTHs are given on the left to demonstrate this point. The stimulus produced by this masking is such that a narrow break in a long slit passes through the center of the receptive field. Therefore, we thought that there might be some elegant mechanism for responding to such a midbreak in the receptive-field organization. We shall discuss this in a later section.

In $56 \%(14 / 25$ cells) of the I-L-type dot-responsive cells (i.e., 


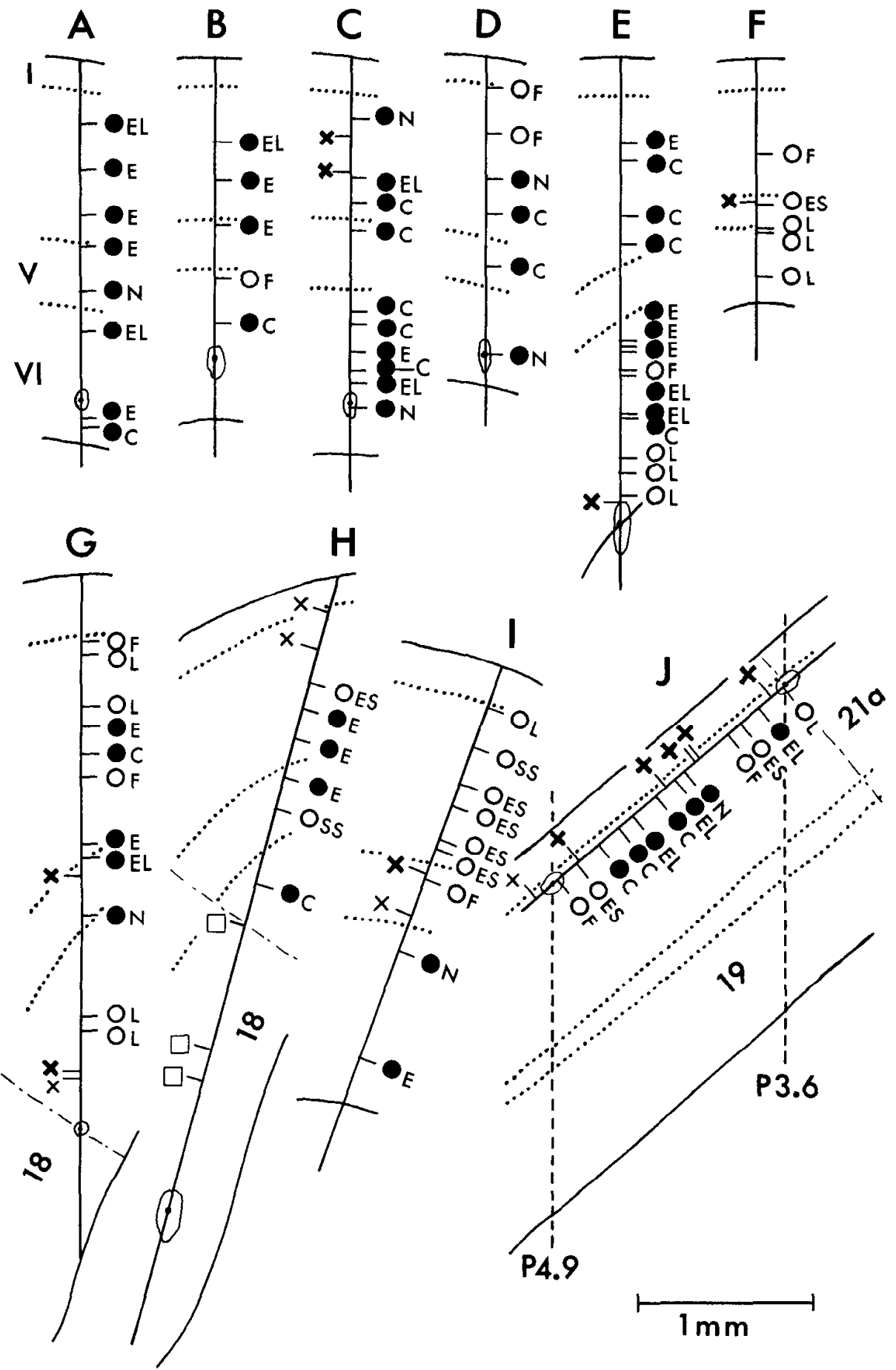

Figure 6. Segregation of cell types within arca 19. The locations of rccorded cells and their response types are shown on histologically reconstructed electrode tracks. The locations of electric lesions are also marked on the tracks. The dotted lines indicate boundaries of layers I, V, and VI. In penetrations that passed through the cortex nearly perpendicularly to the layers (tracks $A-C$, $F$, almost all recorded cells belonged to one of 2 types, namely, the dot-responsive (filled circles) or the elongation-requiring (open circles). On the other hand, in oblique (tracks $D, E, G-$ $I)$ and tangential (track $J$ penetrations, dot-responsive and elongation-requiring cells were recorded alternately in a grouped fashion. These facts indicate that the 2 classes of cells form columns in area 19. With subtypes (indicated by abbreviations) of dot-responsive and elongation-requiring cells, neither columnar nor layer segregation is apparent, though clustering of the same types of cells can be seen. Subtypes of dotresponsive cells: $C$, circular; $E$, elliptic; $E L$, elongated; $N$, nonselective. Subtypes of elongation-requiring cells: $F$, end-free, $E S$, end-stopped; $S S$, singlestopped; $L$, long. Other symbols: open squares, area 18 cells; thin crosses, cells whose responses were too weak (unclassified); thick crosses, unresponsive cells.

the circular and elliptic cells), the inhibition caused by elongation was decreased by more than $50 \%$ by making a narrow break in the middle of the elongated slit. Considering that cells in area 19 are relatively insensitive to stationary stimuli, it is not likely that this effect was caused by the faintly visible mask itself, since it was stationary for a long period. It was confirmed for some cells that a midbreak composed of opposed ends of 2 long slits was a good stimulus for activation. In conclusion, these cells can detect various kinds of discontinuity, i.e., a point, a single termination, and a break in the middle of a long line, which distinguish them clearly from a continuous long line.

\section{Response of end-stopped cells of area 19 to discontinuities}

In order to find out whether the discontinuity-sensitive property is unique to dot-responsive cells of the I-L type, we examined the response of end-stopped cells, which are also insensitive to a long line, to an end of and a midbreak in a long slit. The tests were made on 11 cells. One cell did not respond at all to an end. Excluding 3 cells that were classified as single-stopped, the rest ( 7 cells) gave a response to an end coming from either direction along their preferred orientation, but this was less than $50 \%$ of the maximum response to the optimal stimulus, as shown 

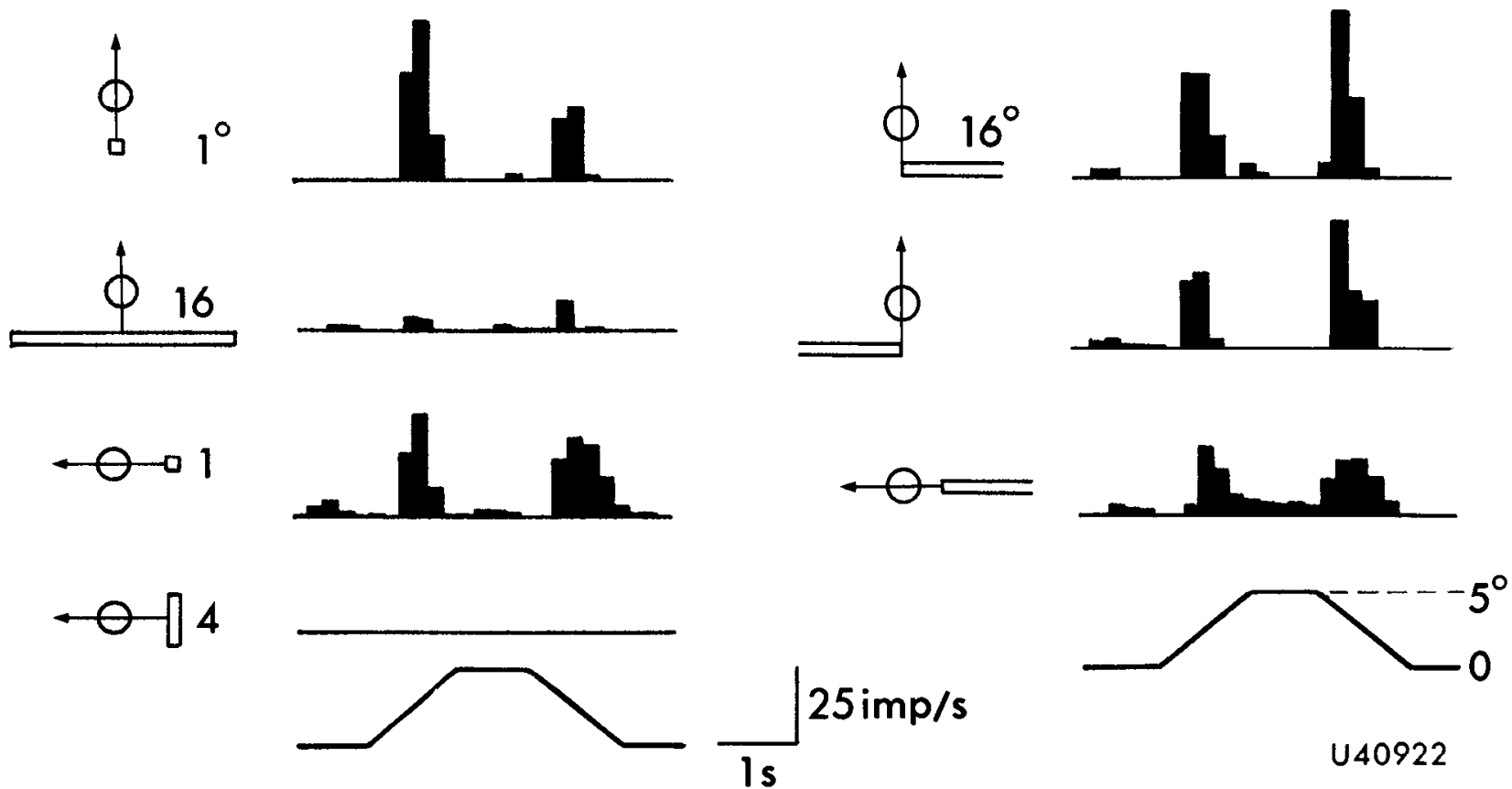

U 40922

Figure 7. Response of a dot-responsive elliptic cell to an end of a long slit. Lef $f$ column. The cell gave a strong response to a $1^{\circ} \times 1^{\circ}$ slit, but the response was eliminated by elongating the slit in either of 2 orthogonal orientations, though the effective length for suppression was different for each of the 2 orientations. Right column, The same cell responded vigorously to a long slit if one end passed through the center of the receptive field. Neither the direction from which the end appeared nor the direction of motion of the end was crucial.

in Figure 9. These observations are consistent with those of Orban et al. (1979a), who found that orientation-selective cells of the end-stopped type in area 17 showed strong end-inhibition to a unilaterally elongated bar stimulus. No end-stopped cells of the 7 cells tested (including 3 single-stopped cells) responded to a mid-break in a long slit.
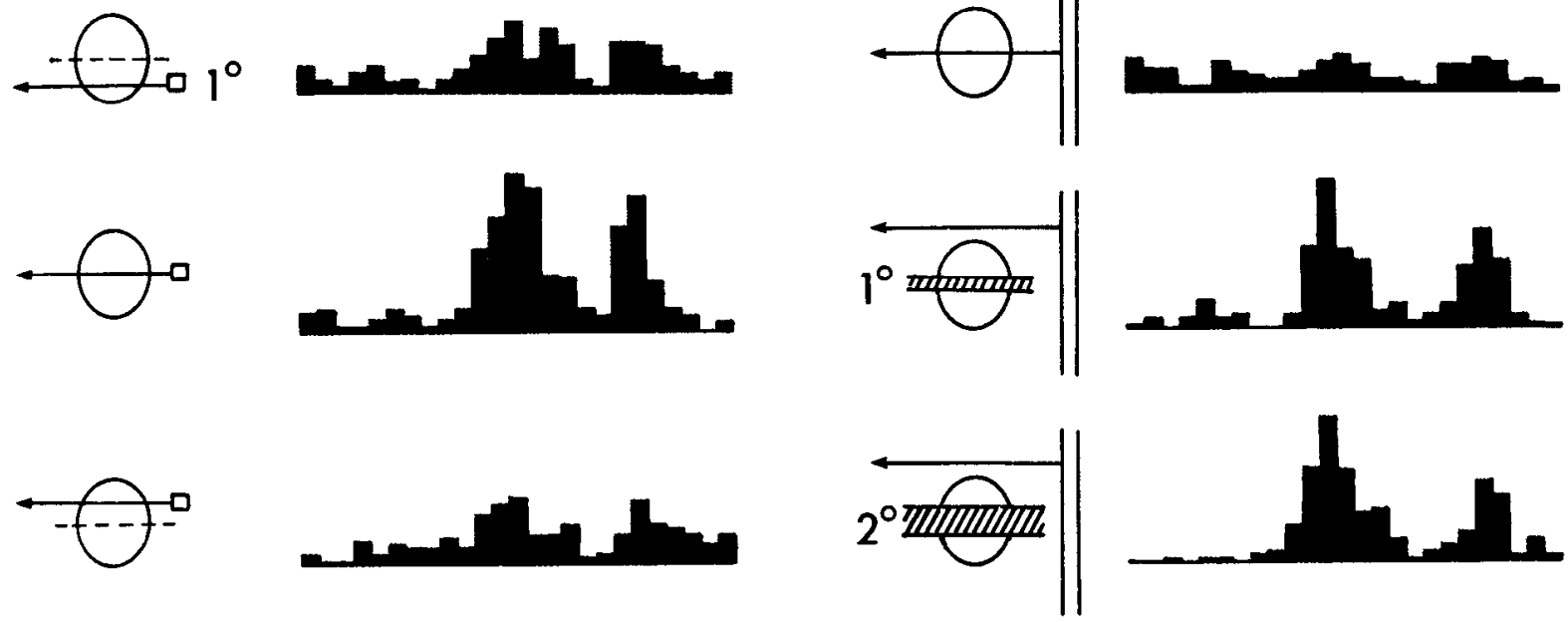

A10039
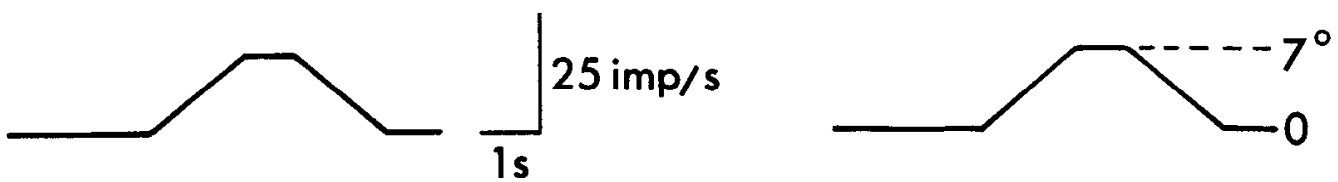

Figure 8. Response of a dot-responsive circular cell to a mid-break in a long slit. The cell did not respond to the passage of a continuous long slit elongated across the receptive field (top right). When a central narrow region of the receptive field was masked from stimulation, the cell responded to the passage of the same long slit vigorously. The width of the mask was not critical (lower 2 PSTHs). The left column demonstrates that the stimulation of the masked region only gave rise to a strong excitation, but not to an inhibition. 

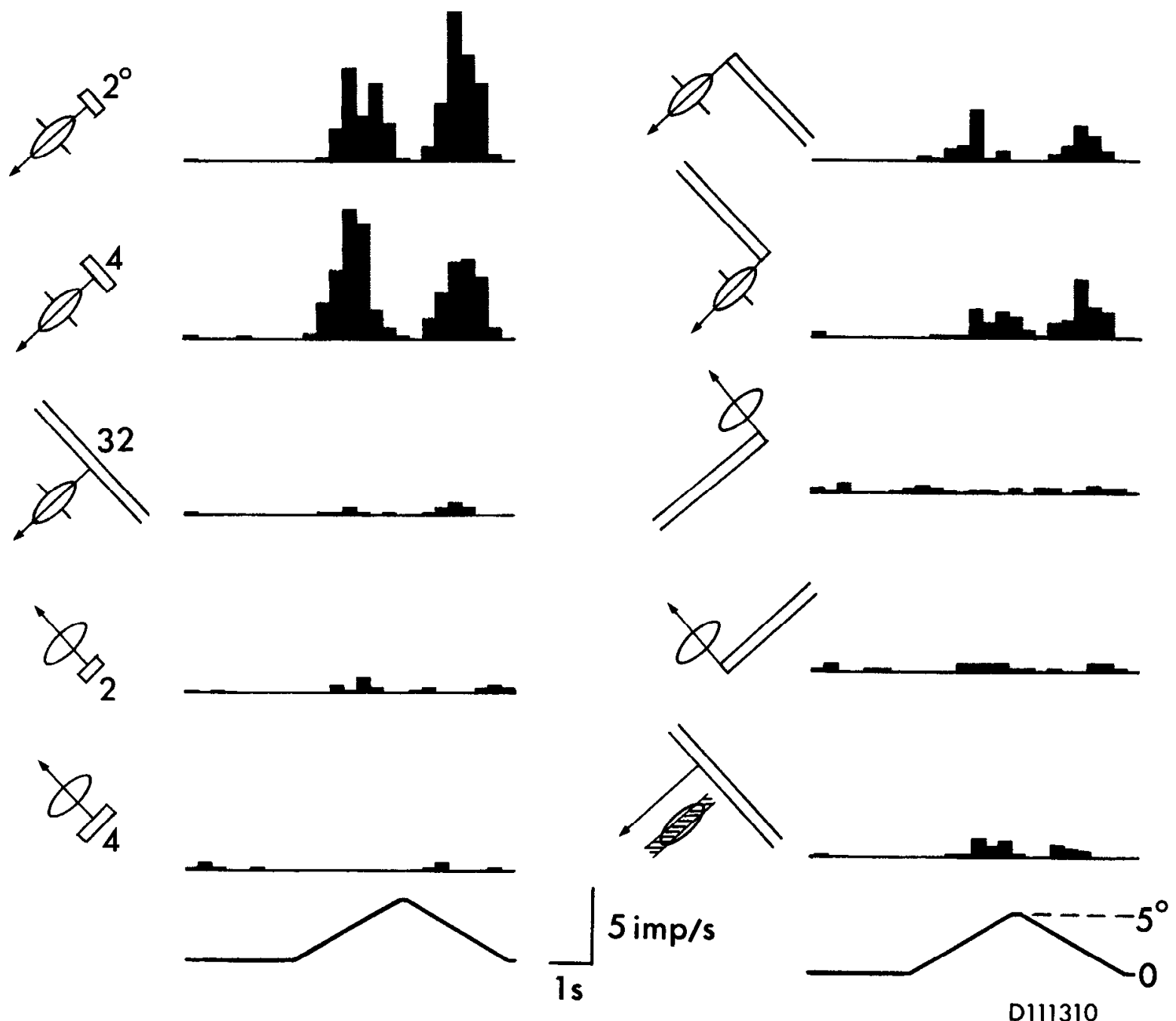

Figure 9. Response of an elongation-requiring, end-stopped cell to an end of, and a midbreak in, a long slit. Left column, Response behavior by which the cell was classificd as an clongation-requiring, end-stopped type cell. Right column, The upper 4 PSTHS show the response of the cell to ends of a long slit appearing from different directions. The cell responded when the orientation was in its preferred orientation (upper 2 PSTHs), but the response was less than $50 \%$ of that to an optimal stimulus (top left PSTHs). The response of the cell to a midbreak was negligible (bottom right PSTHs).

\section{Responsiveness of cells in area 17 to discontinuity stimuli}

Although the population of dot-responsive cells of the I-L type is very small $(9 \%, 12$ cells) in area 17 (Fig. 2), we examined whether they respond to ends and mid-breaks, as they do in area 19 . While 9 out of 11 cells responded significantly to the end of a long slit, no cell (10 cells tested) responded to a midbreak in a long slit. As for end-stopped cells in area 17, their responsiveness to ends was as low as it was in the corresponding type of cells in area 19. Eight cells out of 9 cells tested responded to the end of a long slit, but the strength of the response was less than $50 \%$ of that to an optimal stimulus. No cells ( 7 cells tested) responded to a mid-break in a long slit.

\section{Discussion}

\section{Differences between areas 19 and 17}

Our classification of cells in areas 19 and 17 from the viewpoint of responsiveness to a small, nonoriented stimulus uncovers several new points that are not clear in oriented/nonoriented classifications. First, there is a distinct difference between areas
19 and 17 in the ratio of the population of dot-responsive to elongation-requiring cells. In area 19 , dot-responsive cells $(63 \%$ of classified cells) overwhelm elongation-requiring cells (37\%), whereas in area 17 , the proportion is almost reversed $(28 \%$ versus $72 \%$ ). This difference is independent of retinal eccentricity. Second, histological examination has revealed a columnar organization in area 19 , that is, dot-responsive and elongation-requiring cells form discrete patches in this area. One reason why the dot-responsive property of cells in area 19 has not aroused interest for a long time might be that such a property is very common in the distal part of the visual system.

On the other hand, we confirmed the results of earlier studies, in that the proportion of cells whose responses are inhibited by an elongation of the stimulus bar is distinctly higher in area 19 than in area 17. Such cells in area 19 (including circular and elliptic types of dot-responsive cells-I-L-type dot-responsive cells-and the end-stopped type of elongation-requiring cell) constitute $51 \%$ of classified cells, whereas in area 17 they make up only $23 \%$. Despite the difference in classification, these values are not very different from those given by Duysens et al. (1982a; 
Figure 10. Model considerations for receptive-field mechanisms of I-L-type dot-responsive cells that respond to a mid-break. $A$, and $B$, Models composed of a central excitatory and a surrounding inhibitory region. Inhibition by elongation of a slit can be interpreted by this model, but cells having this type of receptive field may respond weakly to an end and may not respond at all to a mid-break in a long slit, since such stimuli will activate inhibitory mechanisms. $C$, A model receiving converging inputs from several single-stopped cells. The excitatory receptive fields of the single-stopped cells overlap, but their asymmetrical inhibitory regions are oriented in different directions. This model will give a nonoriented response to a short slit and an end of a long slit, but not to a mid-break. $D$, A nonlinear inhibition model that assumes an "and" operation to activate an inhibitory mechanism. This model can simulate the response behavior of I-L-type dotresponsive cells, which respond to a mid-break of a long stimulus. Detailed explanations are given in the text. For all models, the dotted area indicates the excitatory region and the hatched area the inhibitory region of the receptive field.
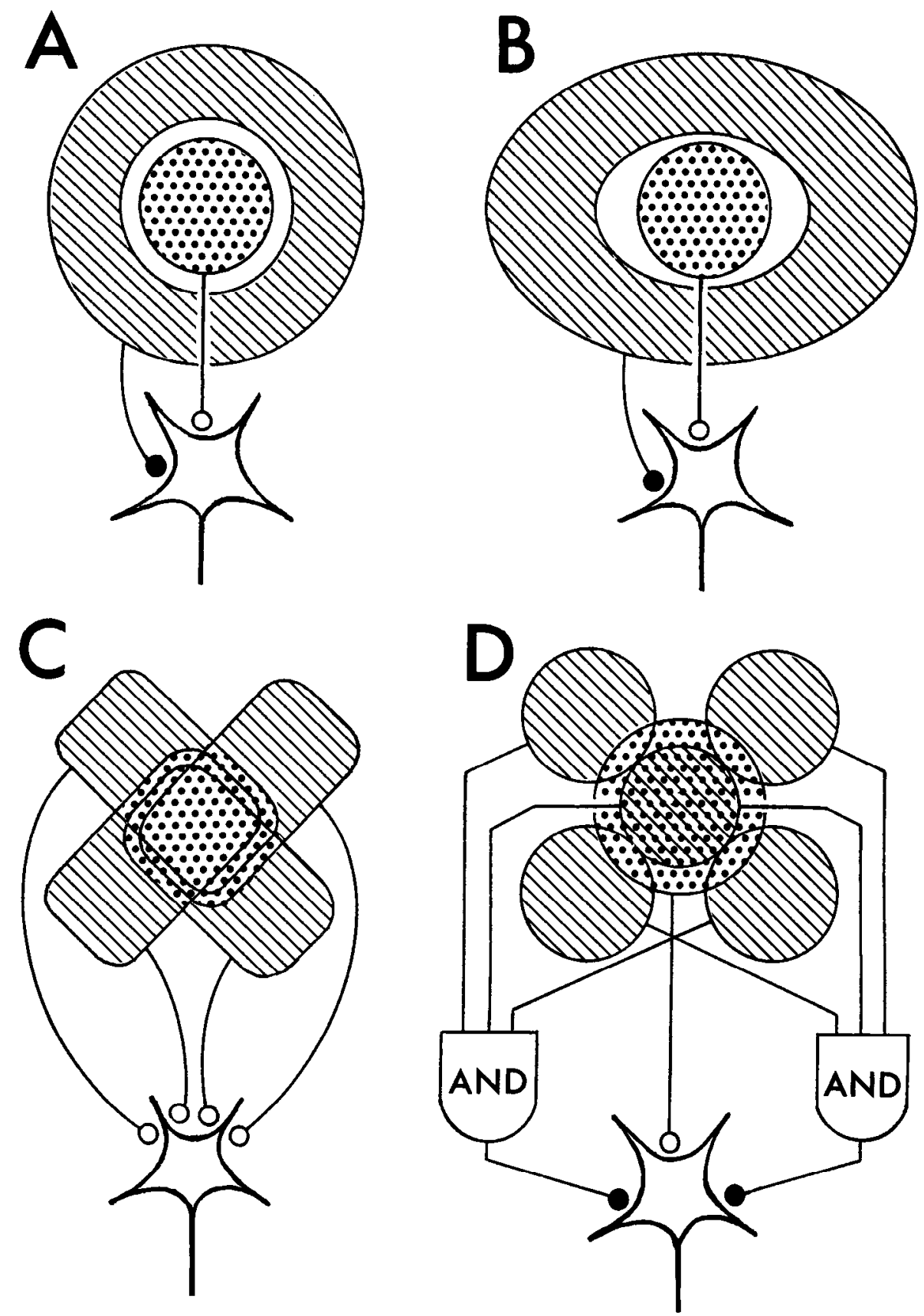

$66 \%$ and $36 \%$ for areas 19 and 17 , respectively). The present study revealed a new aspect of inhibition-by-elongation: many I-L-type dot-responsive cells in area 19 respond well to a long bar if a small break is made in the middle, whereas cells of a similar type in area 17 and end-stopped cells of the elongationrequiring type in both areas scarcely respond to such a midbreak discontinuity. This means that the mechanism and functional meaning of the inhibition-by-elongation are different for different cell classes and areas.

\section{Receptive-field organization of I-L-type dot-responsive cells}

Many workers have analyzed intensively the receptive-field mechanism of orientation-selective cells with end-stopping (Sillito, 1977; Sillito and Versiani, 1977; Henry et al., 1978; Kato et al., 1978; Orban et al., 1979a, b; Yamane et al., 1985; Bolz and Gilbert, 1986). Our present observations of the receptive field of end-stopped cells did not produce any new finding. We shall therefore concentrate on the receptive-field organization of the dot-responsive cells of the I-L type (circular and elliptic types), which were newly identified in the present study.

A receptive field that reponds to a small spot strongly, but is insensitive to the passage of a long contour, can easily be constructed by arranging excitatory and inhibitory regions concentrically, as in Figure $10, A, B$. The inhibitory field should be arranged in a circle around a central excitatory field for dotresponsive circular cells (Fig. 10A), whereas the shape-at least of the inner margin-should be elliptical in elliptic cells (Fig. $10 B$ ). These models, however, show a weaker response to the end of a long slit, which stimulates one side of the inhibitory region, than to a short stimulus, which does not enter the in- 
hibitory region, and therefore they are inadequate for the interpretation of the properties of most dot-reponsive circular and elliptic cells, which responded to an end as strongly as to a short stimulus. One might assume that the inhibition is exerted by elongation-requiring long cells in place of the concentric inhibitory surround, but this model is also inadequate for the same reason.

To overcome this, one may assume a hierarchical integration of the output of several single-stopped cells with different preferred orientations (Fig. 10C). We think that the behavior of some circular and elliptic cells that do not respond to a midbreak in a long slit can be explained by such a hierarchical integration. However, such cells cannot be a building block of the receptive field of dot-responsive cells that respond to a mid-break, since the response of single-stopped cells to the end of a properly oriented slit disappears completely if another end approaches from the opposite side.

Special attention should be paid to the fact that the cells are inhibited only when the center and both end zones of the receptive field are stimulated simultaneously. We noticed that this mode of operation is like the "and" operation in Boolean algebra. In the model shown in Figure $10 D$, we assume that the inhibition works through an "and" operation for inputs coming from the 3 parts of the receptive field-namely, the central region and both end zones - in each of several orientations. Under this assumption, the inhibition disappears if at least one of the 3 regions is not stimulated. One more assumption is needed for the cell to respond to a mid-break in a long line: the summing area for the central excitation should be greater than that for the central inhibition. If the extent of the excitatory region is comparable to that of the central inhibitory rcgion, a mid-break that activates the excitatory mechanism effectively will also activate the central inhibitory mechanism.

For a neuronal mechanism that would perform an "and" operation, we have only to introduce a threshold nonlinearity in a single neuron. That is, if the firing threshold of a neuron is a little greater than the postsynaptic potential change caused by the simultaneous input from any 2 receptive regions, the neuron will fire only if a third input is fed simultaneously.

There are at least 2 candidates for a source of excitation caused by stimulation with a small spot. One is the dot-responsive cells in area 17, though their number is small. Indeed, heavy fiber projections from area 17 to area 19 have been demonstrated (Kawamura, 1973; Gilbert and Kelly, 1975; Montero, 1981; Bullier et al., 1984; Symonds and Rosenquist, 1984; Sherk, 1986; for a review, see Stone et al., 1979), although the receptivefield types of arca 17 cclls that project into area 19 have not been identified.

The other possible source is a subcortical input. There is considerable anatomical evidence that several thalamic nuclei, for example, the $\mathrm{C}$-laminae and the medial interlaminar nucleus (MIN) of the dorsal lateral geniculate nucleus (LeVay and Gilbert, 1976; Holländer and Vanegas, 1977; Leventhal et al., 1980; Niimi et al., 1981) and a lateral part of the lateral posterior nucleus (LPl; Symonds et al., 1981; Berson and Graybiel, 1983; Sherk, 1986) send fibers directly to area 19

Though we showed that the dot-responsive cells in area 17 do not respond well to a mid-break discontinuity, it is still possible that some dot-responsive subcortical cells respond to such a discontinuity, since different groups of subcortical cells project to the 2 areas (Stone et al., 1979). However, to our knowledge no one has identified subcortical cells that respond to a mid-break discontinuity while not responding at all to a continuous long line.

\section{Functional implications}

The present study opened a new window on the functions of area 19. We showed that dot-responsive cells form a major population of area 19. Since most dot-responsive cells of area 19 did not respond to the passage of the middle part of a continuous long contour, but responded strongly to a spot and an end of a long bar in any orientation, while many also responded strongly to a mid-break in a long slit, we believe that the function of such dot-responsive cells must be the detection of discontinuities in visual contours. Though dot-responsive cells are also found in area 17, they are a minority of the cells and do not show high sensitivity to discontinuitics. Thereforc, we suggest that a unique function of area 19 is to form a map of the positions of discontinuous parts of contours in the visual field. In human psychophysics, it has been shown that the discontinuity in a contour is one of the most conspicuous features that is preattentively perceptible (Treisman, 1986).

In the present study, we used only a single solid contour as a stimulus. An interesting observation of Tanaka et al. (1987) is that some area 19 cells can detect discontinuities in a spatially expanded pattern. That is, the end-inhibition of some cells in area 19 is strongest when the spatial frequency of the stimulus offered to the end zones is the same as that presented to the excitatory region, and the strength of the inhibition decreases as the difference between the spatial frequencies increases. In Tanaka et al.'s classification procedure, such cells are of the endstopped type of elongation-requiring cells or of the elliptic, dotresponsive type of the present study. To determine whether one or both of these types can detect a local discontinuity in spatial frequency, further studies using both a single-bar and a grating stimulus are needed. It is noteworthy that cells that can detect a discontinuity in spatial frequency have also been found in area V4 of the macaque monkey (Desimone et al., 1985).

Next, we will discuss the meaning of analyzing discontinuities of solid contours. There seem to be at least 2 functional aspects: (1) the detection of discontinuous parts as features by which a solid figure may be constructed, and (2) the analysis of discontinuities as the elements of a texture.

Related to the first aspect is an interesting psychophysical observation regarding human subjects: When they are asked to discriminate letters and geometrical patterns, such as triangles, crosses, and squares, they fixate the eyes on discontinuous parts of the pattern, such as ends and branching points of contours, more frequently and for a longer period than they do on continuous long parts (Watanabe et al., 1965; Noton and Stark, 1971). This may imply that information important for pattern discrimination is concentrated at such discontinuous parts.

For the cat, the detection of the terminal point of a moving contour seems to have a special behavioral significance. This animal, especially at a young age, shows the behavior of attacking preferentially the hcad or tail of a moving long object, but scarcely its middle. Dot-responsive cells of the I-L type in area 19 could provide key signals to evoke this behavior.

As for the second aspect, it has been shown that the border of 2 areas of different textures is effortlessly perceptible to a human observer as a subjective contour (Julesz, 1981 a, b, 1984, 1985; Beck, 1982; Marr, 1982; Beck et al., 1983; Treisman, 1986). There are several features whose differences provide a cue for subjective contours, for example, line segments in a 
special orientation, width, or length, and crossings of line segments. Such features have been called "textons" by Julesz (1981a, 1984). It has been shown that the termination of a bar could be one such texture element (Julesz, 1981a, 1984; Marr, 1982).

It has recently been shown that cats also have the ability to make texture segmentation using several textons (Wilkinson, 1986). It is possible that dot-responsive cells of the I-L type in area 19 provide a representation of a kind of texton "termination" that is used for texture segmentation.

Elongation-requiring cells may represent another kind of texton "orientation." Among them, end-stopped cells can code "length" in addition to "orientation." From the context of the texture analysis, it is reasonable to assume that the purpose of the columnar arrangement of dot-responsive and elongationrequiring cells in area 19 is to segregate mappings of the 2 kinds of texton, "termination" and "orientation." Such segregation may assist the higher centers in some way in further processing information in order to discriminate texture boundaries.

From any of these viewpoints, the selectivity of the dot-responsive cells of area 19 seems not to be sufficiently sharp to distinguish one kind of discontinuity from the others, as many of the cells respond to dots, ends of lines, and mid-breaks in long lines indiscriminately. We cannot say at present whether there may be some other areas of the brain in which a more precise analysis of discontinuities takes place to distinguish these differences, or whether a rough analysis is adequate for performing the pattern discrimination required by the cat.

\section{References}

Beck, J. (1982) Textural segmentation. In Organization and Representation in Perception, J. Beck, ed., pp. 285-317, Erlbaum, Hillsdale, NJ.

Beck, J., K. Prazdny, and A. Rosenfeld (1983) A theory of textural segmentation. In Human and Machine Vision, J. Beck, B. Hope, and A. Rosenfeld, eds., pp. 1-38, Academic, New York.

Berson, D. M., and A. M. Graybiel (1983) Organization of the striaterecipient zone of the cat's lateralis posterior-pulvinar complex and its relations with the geniculostriate system. Neuroscience 9: 337372.

Bolz, J., and C. D. Gilbert (1986) Generation of end-inhibition in the visual cortex via intcrlaminar conncctions. Naturc 320:362-365.

Bullier, J., H. Kennedy, and W. Salinger (1984) Branching and laminar origin of projections between visual cortical areas in the cat. J. Comp. Neurol. 228: 329-341.

Desimone, R., S. J. Schein, J. Moran, and L. G. Ungerleider (1985) Contour, color and shape analysis beyond the striate cortex. Vision Res. 25: 441-452.

Doty, R. W. (1971) Survival of pattern vision after removal of striate cortex in the adult cat. J. Comp. Neurol. 143: 341-370.

Dreher, B., A. G. Leventhal, and P. T. Hale (1980) Geniculate input to cat visual cortex: A comparison of area 19 with areas 17 and 18 . J. Neurophysiol. 44: 804-826.

Duysens, J., G. A. Orban, H. W. Van Der Glas, and F. E. De Zegher (1982a) Functional properties of area 19 as compared to area 17 of the cat. Brain Res. 231: 279-291.

Duysens, J., G. A. Orban, H. W. Van Der Glas, and H. Maes (1982b) Receptive field structure of area 19 as compared to area 17 of the cat. Brain Res. 231: 293-308.

Gilbert, C. D., and J. P. Kelly (1975) The projections of cells in different layers of the cat's visual cortex. J. Comp. Neurol. 163: 81106.

Henry, G. H., A. W. Goodwin, and P. O. Bishop (1978) Spatial summation of responses in receptive fields of single cells in cat striate cortex. Exp. Brain Res. 32: 245-266.

Holländer, H., and H. Vanegas (1977) The projection from the lateral geniculate nucleus onto the visual cortex in the cat. A quantitative study with horseradish-peroxidase. J. Comp. Neurol. 173: 519-536.

Hubel, D. H., and T. N. Wiesel (1962) Receptive fields, binocular interaction and functional architecture in the cat's visual cortex. J. Physiol. (Lond.) 160: 106-154.

Hubel, D. H., and T. N. Wiesel (1965) Receptive fields and functional architecture in two nonstriate visual areas (18 and 19) of the cat. J. Neurophysiol. 28: 229-289.

Hughes, H. C., and J. M. Sprague (1986) Cortical mechanisms for local and global analysis of visual space in the cat. Exp. Brain Res. 61: 332-254.

Ikeda, H., and M. J. Wright (1974) Sensitivity of neurones in visual cortex (area 17) under different levels of anaesthesia. Exp. Brain Res. 20: $471-484$

Julesz, B. (1981a) Textons, the elements of texture perception, and their interactions. Nature 290: 91-97.

Julesz, B. (1981b) A theory of preattentive texture discrimination based on first-order statistics of textons. Biol. Cybern. 4l: 131-138.

Julesz, B. (1984) A brief outline of the texton theory of human vision. Trends Neurosci. 7: 41-45.

Julesz, B. (1985) Preconscious and conscious processes in vision. In Pattern Recognition Mechanisms, C. Chagas, R. Gattass, and C. Gross, eds., pp. 333-359, Springer-Verlag, New York.

Kato, H., P. O. Bishop, and G. A. Orban (1978) Hypercomplex and simple/complex cell classifications in cat striate cortex. J. Neurophysiol. 41: 1071-1095.

Kawamua, K. (1973) Corticocortical fiber connections of the cat cerebrum. III. The occipital region. Brain Res. 51: 41-60.

Kimura, M., T. Shiida, K. Tanaka, and K. Toyama (1980) Three classes of area 19 cortical cells of the cat classified by their neuronal connectivity and photic responsiveness. Vision Res. 20:69-77.

LeVay, S., and C. D. Gilbert (1976) Laminar patterns of geniculocortical projection in the cat. Brain Res. 113: 1-19.

Leventhal, A. G., J. Keens, and I. Törk (1980) The afferent ganglion cells and cortical projections of the retinal recipient zone (RPZ) of the cat's "pulvinar complex." J. Comp. Neurol. 194: 535-554.

Livingstone, M. S., and D. H. Hubel (1981) Effects of sleep and arousal on the processing of visual information in the cat. Nature 291: 554561 .

Marr, D. (1982) Vision, Freeman, San Francisco.

Montero, V. M. (1981) Topography of the cortico-cortical connections from the striate cortex in the cat. Brain Behav. Evol. 18: 194-218.

Movshon, J. A., I. D. Thompson, and D. J. Tolhurst (1978) Spatial and temporal contrast sensitivity of neurones in areas 17 and 18 of the cat's visual cortex. J. Physiol. (Lond.) 283: 101-120.

Niimi, K., H. Matsuoka, Y. Yamazaki, and H. Matsumoto (1981) Thalamic afferents to the visual cortex in the cat studied by retrograde axonal transport of horseradish peroxidase. Brain Behav. Evol. 18: 114-139.

Noton, D., and L. Stark (1971) Eye movements and visual perception. Sci. Am. 224: 34-43.

Orban, G. A., H. Kato, and P. O. Bishop (1979a) End-zone region in receptive fields of hypercomplex and other striate neurons in the cat. J. Neurophysiol. 42: 818-832.

Orban, G. A., H. Kato, and P. O. Bishop (1979b) Dimensions and properties of end-zone inhibitory areas in receptive fields of hypercomplex cells in cat striate cortex. J. Neurophysiol. 42: 833-849.

Palmer, L. A., A. C. Rosenquist, and R. J. Tusa (1978) The retinotopic organization of lateral suprasylvian visual areas in the cat. J. Comp. Neurol. 177: 237-256.

Saito, H., K. Tanaka, Y. Fukada, and H. Oyamada (1985) Discontinuity-analysis in the cat's area 19. Soc. Neurosci. Abstr. 11: 1010.

Saito, H., K. Tanaka, and Y. Fukada (1986) Analysis of contours in the area 19 of the cat. Int. Congr. Neuroethol. Abstr. 1: 82.

Sherk, H. (1986) Location and connections of visual cortical areas in the cat's suprasylvian sulcus. J. Comp. Neurol. 247: 1-31.

Sillito, A. M. (1977) The spatial extent of excitatory and inhibitory zones in the receptive field of superficial layer hypercomplex cells. J. Physiol. (Lond.) 273: 791-803.

Sillito, A. M., and V. Versiani (1977) The contribution of excitatory and inhibitory inputs to the length preference of hypercomplex cells in layers II and III of the cat's striate cortex. J. Physiol. (Lond.) 273: 775-790.

Spear, P. D., and T. P. Baumann (1975) Receptive-field characteristics of single neurons in lateral suprasylvian visual area of the cat. $J$. Neurophysiol. 38: 1403-1420.

Sprague, J. M., J. Levy, A. DiBerardino, and G. Berlucchi (1977) Visual cortical areas mediating form discrimination in the cat. J. Comp. Neurol. 172: 441-488. 
Stone, J., B. Dreher, and A. Leventhal (1979) Hierarchical and parallel mechanisms in the organization of visual cortex. Brain Res. Rev. 1: 345-394.

Symonds, L. L., and A. C. Rosenquist (1984) Corticocortical connections among visual areas in the cat. J. Comp. Neurol. 229: 1-38.

Symonds, L. L., A. C. Rosenquist, S. B. Edwards, and L. A. Palmer (1981) Projections of the pulvinar-lateral posterior complex to visual cortical areas in the cat. Neuroscience 6: 1995-2020.

Tanaka, K., I. Ohzawa, A. S. Ramoa, and R. D. Freeman (1987) Receptive field properties of cells in area 19 of the cat. Exp. Brain Res. 65: 549-558.

Toyama, K., and T. Kozasa (1982) Responses of Clare-Bishop neurones to three dimensional movement of a light stimulus. Vision Res. 22: 571-574.

Toyama, K., K. Fujii, S. Kasai, and K. Maeda (1986a) The responsiveness of Clare-Bishop neurons to size cues for motion stereopsis. Neurosci. Res. 4: 110-128.

Toyama, K., Y. Komatsu, and T. Kozasa (1986b) The responsiveness of Clare-Bishop neurons to motion cues for motion stereopsis. Neurosci. Res. 4: 83-109.
Treisman, A. (1986) Feature and objects in visual processing. Sci. Am. 255: 106-115.

Tusa, R. J., and L. A. Palmer (1980) Retinotopic organization of areas 20 and 21 in the cat. J. Comp. Neurol. 193: 147-164.

Tusa, R. J., L. A. Palmer, and A. C. Rosenquist (1978) The retinotopic organization of area 17 (striate cortex) in the cat. J. Comp. Neurol. 177: 213-236.

Tusa, R. J., A. C. Rosenquist, and L. A. Palmer (1979) Retinotopic organization of areas 18 and 19 in the cat. J. Comp. Neurol. 185: 657-678.

Watanabe, A., K. Hiwatashi, N. Hatanaka, and S. Tanaka (1965) Figure and distribution of fixation point. NHK Technical J. 17: 4-20.

Wilkinson, F. (1986) Visual texture segmentation in cats. Behav. Brain Res. 19: 71-82

Yamane, S., R. Maske, and P. O. Bishop (1985) Properties of endzone inhibition of hypercomplex cells in cat striate cortex. Exp. Brain Res. 60: 200-203. 